\title{
La nueva regulación del transfuguismo en el Reglamento parlamentario andaluz
}

Victor F. Vázquez Alonso

El Reglamento del Parlamento andaluz ha sido objeto, con el apoyo de todos los grupos parlamentarios a excepción del de VOX, de una reforma ${ }^{1}$ cuyo significado bien podemos calificar de trascendental, en tanto avanza, como veremos, una interpretación del mandato representativo y, en concreto, de la relación entre el diputado y la formación política en cuyas listas éste concurrió a las elecciones, que intensifica, mucho más allá de lo hasta ahora asumido, el vínculo entre el cargo representativo y el partido político.

Sobre los hechos que dan origen a esta reforma ya hemos tenido ocasión de ocuparnos en el anterior número de esta misma publicación, y no son otros que la expulsión del grupo parlamentario de Adelante Andalucía de los diputados Teresa Rodríguez, Ángela Aguilera, José Ignacio García, Luz Marina Dorado, María Vanessa García, María Gracia González, Nacho Molina y Diego Crespo. El origen de esta expulsión se encuentra en la imputación de transfuguismo tras el abandono por parte de éstos de su militancia en Podemos -formación a través de la cual lograron sus escaños, dentro de la coalición Adelante Andalucía- con el objetivo de crear una formación autónoma. La Mesa del Parlamento andaluz refrendó la decisión comunicada por el portavoz parlamentario de la formación, de tal manera que estos diputados quedaron fuera del grupo Adelante Andalucía, pasando, en virtud de las disposiciones reglamentarias, a ser diputados no adscritos a todos los efectos.

No vamos a insistir de nuevo, por ser bien conocida, en la suerte de "capitis diminutio" que supone para el ejercicio del cargo representativo la exclusión del grupo parlamentario. Sí lo haremos, en cambio, en las muchas dudas que generaba la adecuación jurídica de la decisión tomada por la Mesa en este caso. Dudas que tienen que ver, por un lado, con el propio hecho de que la coalición había conformado sus listas a través de un proceso abierto de primarias, para cuya concurrencia no se exigía la previa militancia política, de tal forma que nos encontramos ante un caso que pone de manifiesto los propios matices con los que, en función de las circunstancias, ha de comprenderse la relación de dependencia entre el candidato electo y el partido o la coalición a través de la cual concurrió en sus listas. Pero, más allá de esto, lo significativo, en este caso, es que el acuerdo de la Mesa se produce en ausencia de

BOPA No 566, 4 de mayo DE 2021, Reforma del Reglamento del Parlamento de Andalucía en relación con los Grupos Parlamentarios (Aprobada en sesión del Pleno del Parlamento de 28 de abril de 2021) 
una previsión reglamentaria expresa, refrendando así el órgano de gobierno de la Cámara, de forma expedita, la decisión de la formación política, aun cuando, como ocurre en este supuesto, eso suponga dejar fuera de la cobertura jurídica del grupo parlamentario a una mayoría de los diputados que integraban el mismo.

La reforma del Reglamento andaluz trata, como veremos, de colmar esta laguna, intensificando la relación de dependencia entre el diputado el partido político de una forma inédita. Como es conocido, el perímetro dibujado por el Tribunal Constitucional, en lo relativo al marco de relación subsistente entre el diputado y la formación política en la que este concurrió a las elecciones, parte de que la condición de representante no puede ser cuestionada por el partido, en tanto eso supondría atentar de manera absolutamente frontal el derecho de los ciudadanos a participar en los asuntos públicos por medio de representantes y también el de los representantes mismos a mantenerse en sus funciones. En cualquier caso, el juez constitucional no ha dejado de atender al hecho de que, en un sistema de listas cerradas y bloqueadas, no puede afirmarse de forma rotunda que "los votos son recibidos por los candidatos y deben imputárseles individualmente a estos", de tal forma que "no cabe hablar de votos recibidos por candidatos singularmente considerados, sino, con relación a estos, de cocientes, que no son votos efectivamente obtenidos, sino más bien resultados convencionales deducidos, a los efectos de reparto, del número total de votos de cada candidatura"2.

Pues bien, dentro de este marco, y a rebufo de la III Adenda aprobada por la Comisión de Seguimiento del Pacto Antitransfuguismo, denominada "Pacto por la estabilidad institucional. Acuerdo sobre un código de conducta política en relación con el transfuguismo en las instituciones democráticas", en la que se establece que "las fuerzas políticas se comprometen a impulsar la modificación, desde el respeto a su autonomía e idiosincrasia, de los reglamentos de las cámaras y los reglamentos orgánicos de las corporaciones locales, para adaptarlos a lo establecido en los Acuerdos y las modificaciones legales que de estos se deriven", el Parlamento Andaluz ha optado por prescindir de cualquier correa de transmisión entre el partido político y el diputado, para situar al primero en el centro mismo de la vida parlamentaria, otorgándole, como ahora vamos a ver, competencias determinantes en la gestión del grupo parlamentario.

A este respecto, llama en primer lugar la atención el hecho de que la nueva redacción del 21.2 del Reglamento, haya incorporado en proceso de constitución del grupo parlamentario, el escrito de conformidad del representante legal del sujeto político que presentó la candidatura, un requisito sin duda revelador del nuevo rol que la norma reglamentaria otorga al partido político en el ámbito puramente parlamentario.

$2 \quad$ STC $64 / 2002, \mathrm{FJ}^{\circ} 5$. 
Por otro lado, el número 3 de este mismo artículo, impone al grupo parlamentario la comunicación de su normativa interna, dentro de la cual habrá de detallarse, junto con la denominación y especificación de los órganos de gobierno, tanto el procedimiento de incorporación como el procedimiento de salida del Grupo. Acto seguido, el 21.4 afirma la autoridad del Portavoz del Grupo parlamentario, o su adjunto, para llevar a cabo las facultades, funciones o actuaciones atribuidas al grupo parlamentario.

Por su parte, el 24.2, regula la baja en el grupo parlamentario y la adquisición de la condición de diputado no adscrito, que deberá ser reconocida por la mesa, en tres supuestos, a) Por abandono voluntario del Diputado o Diputada, que surtirá efecto cuando el Diputado o Diputada afectado comunique tal circunstancia a la Mesa del Parlamento de Andalucia. b) Por expulsión motivada del Grupo parlamentario en aplicación de las causas expresamente previstas en la Normativa Interna a la que se refiere el artículo 21.3 de este Reglamento, y finalmente, c) En el supuesto de transfuguismo, siendo aquí especialmente relevante el hecho de que, en este supuesto, la comunicación a la Mesa del abandono, expulsión o separación del criterio político fijado por sus órganos competentes del Diputado o Diputada que concurrió por la candidatura de la que trae causa el Grupo parlamentario corresponderá al representante legal del sujeto político que presentó la candidatura o al del partido político que propuso su inclusión en esta en caso de coalición electoral. Es decir, que es, en último término, el partido político o agrupación de electores, quien puede determinar la expulsión del grupo parlamentario, siendo muy limitada la propia función de control que puede llevar aquí la Mesa, a la hora de velar por la integridad en el ejercicio de sus funciones parlamentarias de aquellos diputados afectados por la decisión y que adquirirán desde ese momento la condición de no adscritos.

A este respecto, el propio artículo 24 establece que, sin perjuicio de las previsiones adicionales que la Normativa Interna del Grupo parlamentario pueda contener sobre la baja, para tener esta por acreditada, con los efectos consiguientes, la Mesa del Parlamento de Andalucía se limitará a comprobar, conforme al procedimiento de acreditación establecido, que el acuerdo de baja ha sido adoptado por el órgano o las personas competentes, con las mayorías en su caso previstas, y que la causa invocada se halla expresamente prevista en la Normativa Interna del Grupo parlamentario.

Del mismo modo, la nueva Disposición Adicional Quinta, va a acotar el concepto de tránsfuga, en sintonía con la nueva Adenda ya mencionada al pacto antitransfuguismo, para considerar como tránsfugas a aquellos diputados que, traicionando al sujeto político (partido político, coalición electoral o agrupaciones de electores) que los presentó a las elecciones, hayan abandonado el mismo, hayan sido expulsados o se aparten del criterio fijado por sus órganos competentes. E igualmente, puntualiza este artículo, se considerará tránsfuga... al Diputado o Diputada electo por una candidatura promovida por una coalición, si abandona, se separa de la disciplina o es expulsado del partido político coaligado que propuso su incorporación 
en la candidatura, aunque recale en otro partido o espacio de la coalición sin el consentimiento o tolerancia del partido que originariamente lo propuso. Llama sin duda la atención, de este intento por parte del Parlamento de cerrar la definición de tránsfuga, el hecho de que se haya recurrido a un término, en principio tan ajeno al lenguaje jurídico, como es el de la traición, que, precisamente por esa ajenidad e indeterminación, puede ser presupuesto un para uso arbitrario por parte de los partidos políticos, con el consiguiente menoscabo de la autonomía mínima predicable de la función representativa.

La reforma ha servido también para perfilar el estatus de la figura, ya prevista en el derecho parlamentario andaluz desde la reforma de 2003, del diputado no adscrito, quienes gozarán únicamente de los derechos reconocidos reglamentariamente a los Diputados individualmente considerados, exceptuándose expresamente aquellos previstos para los Grupos parlamentarios o las actuaciones agrupadas de Diputados establecidas en el presente Reglamento, y que, cuando adquieran tal condición, dejarán de ocupar cualquier puesto o cargo en los órganos del Parlamento o de ostentar la condición de miembros de aquellos, sin perjuicio de su posterior elección o designación conforme a los procedimientos establecidos. Si bien, como establece el 26.3, en cualquier momento el Diputado o Diputada no Adscrito podrá retornar al Grupo parlamentario al que hubiese pertenecido, siempre que medien el consentimiento y la firma de su Portavoz.

Del mismo modo, el 26.7 determina ahora que cuando el número de Diputados no Adscritos altere significativamente la proporcionalidad prevista en el artículo 103.4, in fine, del Estatuto de Autonomía para Andalucía, podrá establecer fórmulas que repongan la representación política emanada del proceso electoral, incluida la del voto ponderado, sin que se produzca en ningún caso la sobrerrepresentación de los Diputados no Adscritos. Asimismo, dichas fórmulas se podrán establecer en los supuestos en que la composición del Grupo Parlamentario Mixto comprometa el principio de proporcionalidad.

Por otro lado, la nueva regulación vela específicamente para que la expulsión o baja de diputados de un grupo no modifique el estatuto jurídico que este obtuvo como consecuencia de su constitución. De esta forma, se establece que cualesquiera derechos, facultades, funciones, posibilidades de actuación y medios reconocidos a los Grupos parlamentarios en este Reglamento y demás normativa parlamentaria lo serán sobre la base del número de Diputados obtenidos por la candidatura electoral en la que concurrieron a las elecciones y de la que el Grupo parlamentario trae causa, sin que resulte relevante el número de Diputados con que cuente en cada momento el Grupo parlamentario. Ahora bien, todo esto con la excepción expresa de los supuestos de ponderación de voto.

Durante la tramitación de esta reforma, quien es, a buen seguro, el mejor conocedor del derecho parlamentario andaluz, el profesor José María Morales, escribió que las modificaciones anunciadas proyectaban "inquietantes expectativas para el futuro del parlamentarismo andaluz". En su opinión, con esta reforma, finalmente consolidada, "el Parlamento cedería gran parte de su autonomía decisoria en favor 
de entes externos indeterminados (partidos, coaliciones de partidos, federaciones), con órganos que podrían decidir desde fuera del Parlamento y hasta de Andalucía, y renunciaría a que sus órganos continúen siendo los garantes del pluralismo político y de las minorías". En el momento de entregar esta crónica, otro experto en derecho parlamentario, Carlos Fernández Esquer, apuntaba también a la "inquietud democrática" y al pernicioso precedente que dicha reforma supone, en tanto desincentiva "cualquier atisbo de sana discrepancia dentro de los márgenes de la coincidencia ideológica y programática que se le presupone al parlamentario respecto a su partido". Cabe terminar esta crónica haciendo nuestras estas críticas, que van de la mano de las propias dudas de constitucionalidad que plantea una alteración de la lógica del mandato representativo como la aprobada, que consolida jurídicamente una forma de entender la relación entre el diputado y el partido político marcada por el vasallaje, y en la que se hace ya difícilmente reconocible la esencia de la función representativa. 